\title{
PSYCHE.
}

\section{THE LIFE HISTORY OF SPALGIS S-SIGNATA HOLL.}

BY W. J. HOlland, Ph.D., PitTsburgh, PEnN.

In November of last year I published in Psyche, vol. 5, p. 426, a description of a new species of Spalgis Moore, from Kangwe, upon the Ogové River, West Africa, and gave to it the specific name s-signata.

I have recently received the larva and chrysalis of the insect, accompanied by a note from the collector, Rev. A. C. Good, Ph.D., which shows that we are dealing with a species, which is in its habits closely related to our own Feniseca tarquinius Fabr. The creature is aphidivorous in its larval state, as Mr. Good shows. We thus have knowledge of four species of Lycaenidae, the caterpillars of which are characterized by carnivorous propensities. They are

Feniseca tarquinius Fabr.,

Spalgis epius Westwood,

Liphyra brassolis Westwood,

Spalgis s-signata Holland.

The life history of Feniseca tarquinius has been thoroughly worked out by Miss Emily Morton and Mr. W. H. Edwards. The life history of Spalgis epius, as given by Mr. E. E. Green, of Pundul-oya, Ceylon, and incorporated in vol. 2 of the "Butterflies of India, Burmah, and Ceylon," by De Nicéville, finds confirmation in the discovery of Rev. Mr. Good. Mr. Green calls attention in loc. cit. to the fact that there must have been an error made in assigning to S. epius the larva and chrysalis which are attributed to that species in Mr. Moore's great work upon the Lepidoptera of Ceylon. That the larva of Liphyra brassolis is aphidivorous is an inference of the writer, and is based upon grounds, which he has fully detailed in the Canadian entomologist, vol. 19, p. 6r. Undoubtedly, as we come to a fuller knowledge of the habits of the Lycaenidae of the tropics of the old world, we shall find that there are several genera besides those which have been named that have similar habits. I strongly suspect that the larvae of Lachnocnema and of Euliphyra mihi, are like the larvae of Spalgis and Feniseca in their food habit.

I give upon Plate 4 the figure of the larva, the chrysalis, and the imago of Spalgis s-signata, and have also given a magnified representation of the dorsal 
aspect of the chrysalis, which excited very naturally the surprise of Mr. Good, as his note which I append to this brief account shows. It is worthy of remark that the same strange likeness to a human face which is found in S. s-signata, is observable in Feniseca tarquinius. In the notes sent to Mr. Edwards by Miss Morton, and published in the Canadian entomologist, vol. r8, p. I47, she asks "Have you noticed the ape's face which the chrysalis shows?"

While Mr. Good regrets that he was unable, in inflating the larval skin, to preserve the white matter adhering to it, there is, nevertheless, a good deal of it clinging to it. Examined under a powerful microscope this adhering matter is seen to present a peculiar shining appearance, and to thickly cover the hairs with minute granulations as if each hair had been dipped in some substance like a solution of sugar or salt, and then had been dried. I herewith give Mr. Good's notes:

\section{January igth, i 89 I.}

"Today I stumbled upon the queerest object which I think I ever saw. On the underside of the leaves of a fragipanni I saw a number of small chrysalids which bore a most absurd resemblance to a human face. I found a few of the larvae still unchanged. Their color was dark brownish, but I have inflated one, and that will be better than any description. The body was all covered over with a whitish substance, not a part of the body, and which I took to be the remains of plant lice with which the underside of the leaves on which the larvae were found abounded. I think that these caterpillars must have fed upon these white plant lice, for I could not detect that they had eaten the leaves. Almost all of the white foreign substance is rubbed off of the specimen which I inflated, and I regret that I did not succeed better in preserving the specimen just as it appeared. The chrysalis is attached to the leaf by the back of the head,* and presents to view what mimics in a wonderful way the face of a man or a chimpanzee. Especially do the eyes and the well-marked brows overhanging them present a startling resemblance to the human face. The natives notice and are surprised at the resemblance as much as I am. Here is mimicry, but to what possible purpose? Or has Dame Nature for once laid aside her usually practical character and decided to amuse herself? I hope I may be able to preserve and send a chrysalis intact."

January $24^{\text {th }}, \mathrm{I} 89 \mathrm{r}$.

"Today two of No. ro have emerged, and I am pleased to find that we are dealing with a rare butterfly. The empty shells show nothing of the resemblance to a human or monkey face of which I have spoken previously. I have therefore dried a chrysalis, and have succeeded well, except that one eye looks a little bloodshot. I hope that you can make out the exact appearance of the chrysalis."

* Mr. Good, when speaking of the "head" in this connection, is not employing technically accurate language, but is accommodating his phrase to the appearance of the chrysalis. The mode of attachment is pre. cisely like that to be observed in Feniseca tarquinius. 
Psyche, 1892, Vol. 6.

Plate 4

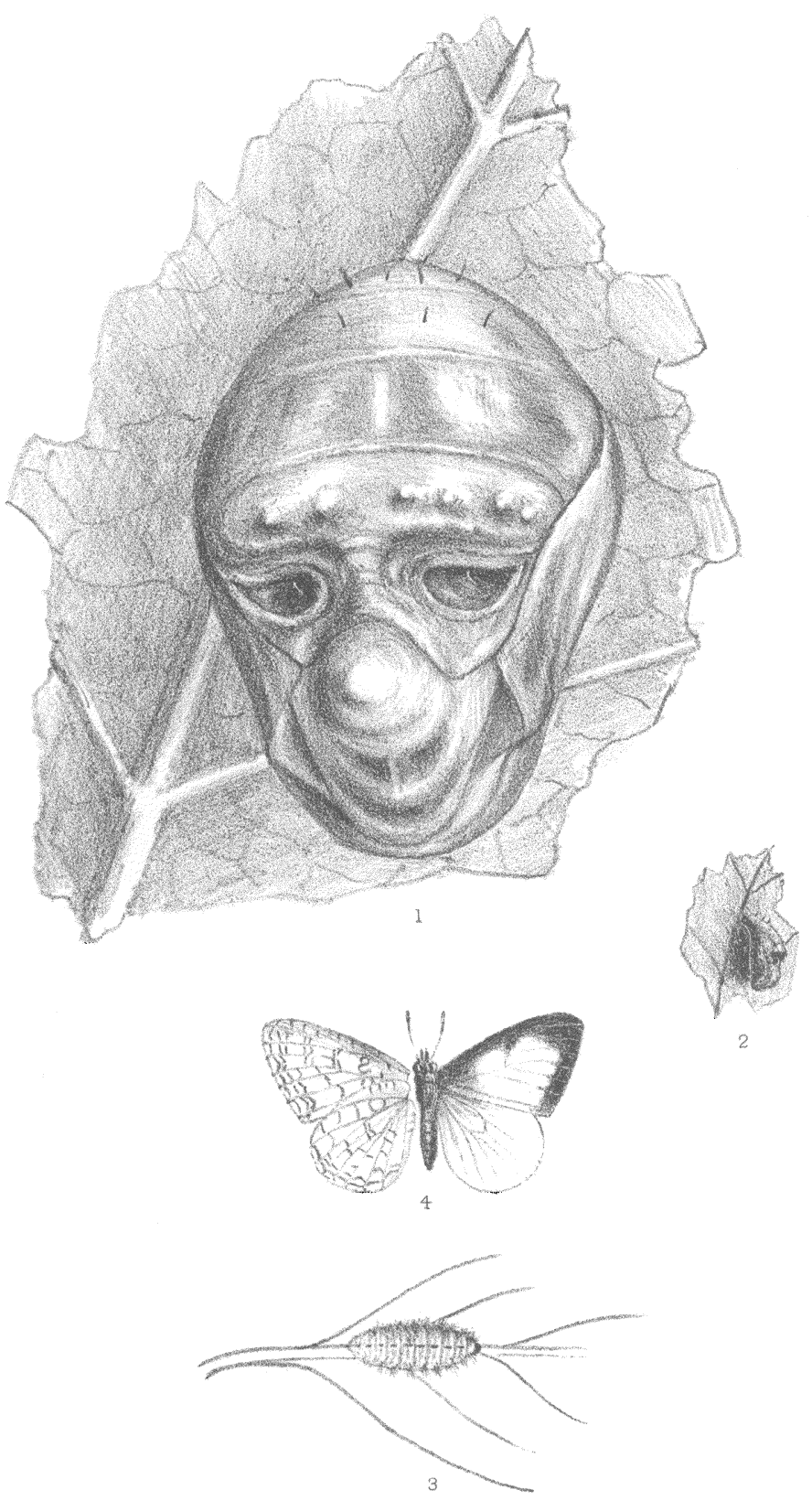


Later.

"Fourteen butterflies emerged from the chrysalids, but some of them did not disclose the imago, but dried up in the box, retaining their natural appearance. I send these in a roll of paper."
Explanation of Plate 4.

Fig. I. Spalgis s-signata Holland. Chrysalis enlarged.

Fig. 2. Same. Chrysalis, nat. size.

Fig. 3. Same. Larva.

Fig. 4. Same. Imago.

\section{LIFE HISTORY OF ORGYIA CANA HY. EDW.}

BY IIARRISON G. DYAR.

\section{Orgyia cana Hy. Edw .}

I881.-H. Edwards, Papilio, v. I, p. 62.

Egg. Slightly conoidal though almost spherical, smooth, shiny, opaque white, with a faint brownish spot and ring at the flattened end; diameter $\mathrm{I} \mathrm{mm}$. The eggs are laid in a mass on the cocoon of the female moth, fastened together by a slight amount of froth and thickly covered with the faintly brownish down from the body of the moth. The winter is passed in this stage, the little larvae hatching in the spring and emerging as mature moths in July and August. There is but one brood a year.

First larval slage. Head shining black, labrum a little paler; width o $4 \mathrm{~mm}$. Body sordid purplish black, a dorsal yellowish shade on joints 3,4 and 9 and a whitish stigmatal line. Warts black, the subdorsal ones on joint 2, large; hair thin, but several hairs grow from each wart, black. There are no brush-like tufts, hair pencils nor retractile tubercles, but the places of the latter are indicated by a dorsal red spot on joints ro and I r respectively, not elevated.

Second stage. Head brownish black, shiny; width $0.7 \mathrm{~mm}$. Body and warts black, hair thin, bristly and black. The subdorsal warts on joint 2 are large, but there are no brush tufts nor pencils. The retractile tubercles are present on joints Io and II, small, and colored dull blood red. The dorsum is paler on joints 3,4 and 9 .
Third stage. Head black with a brownish tinge, labrum white; width I.I-I.3 mm. Body black except on the dorsum of joints 3 and 4 where it is yellowish white with a black dorsal line, and also a yellowish subdorsal spot on joints 9 and ro (anteriorly). Warts all black; hair long, black with pencils of short, plumed, black hairs from the subdorsal warts of joint 2 (none on joint 12 ). There are small, dorsal, black, brush-like tufts on joints 5 and 6 and a few short tufted white hairs on joints 7 and 8 . The warts of row 2 on joint 9 are a little tinged with red. Retractile tubercles red. Length of larva about $9 \mathrm{~mm}$.

Fourth stage. Head brownish black, labrum and antennae sordid white; width r.7I. $8 \mathrm{~mm}$. Body greenish black below, gray on the sides, a black subdorsal and yellow subventral line. Dorsum largely sordid yellow; cervical shield, a dorsal line on joints 3 and 4 , a shade surrounding the tufts on joints $5-8$, and a broad band from joint 9 posteriorly to joint I2, all black; joint 13 dark gray. The warts of rows $x-5$ and the retractile tubercles are all blood red, concolorous, except those on joint 2 which are black. The plumed pencils on joint 2 are $2.5 \mathrm{~mm}$. long, and there is now also one on joint 12 dorsally. The brush-like tufts on joints 5 and 6 are brown, those on 7 and 8 white. The other hair is long and black but whitish subventrally. 

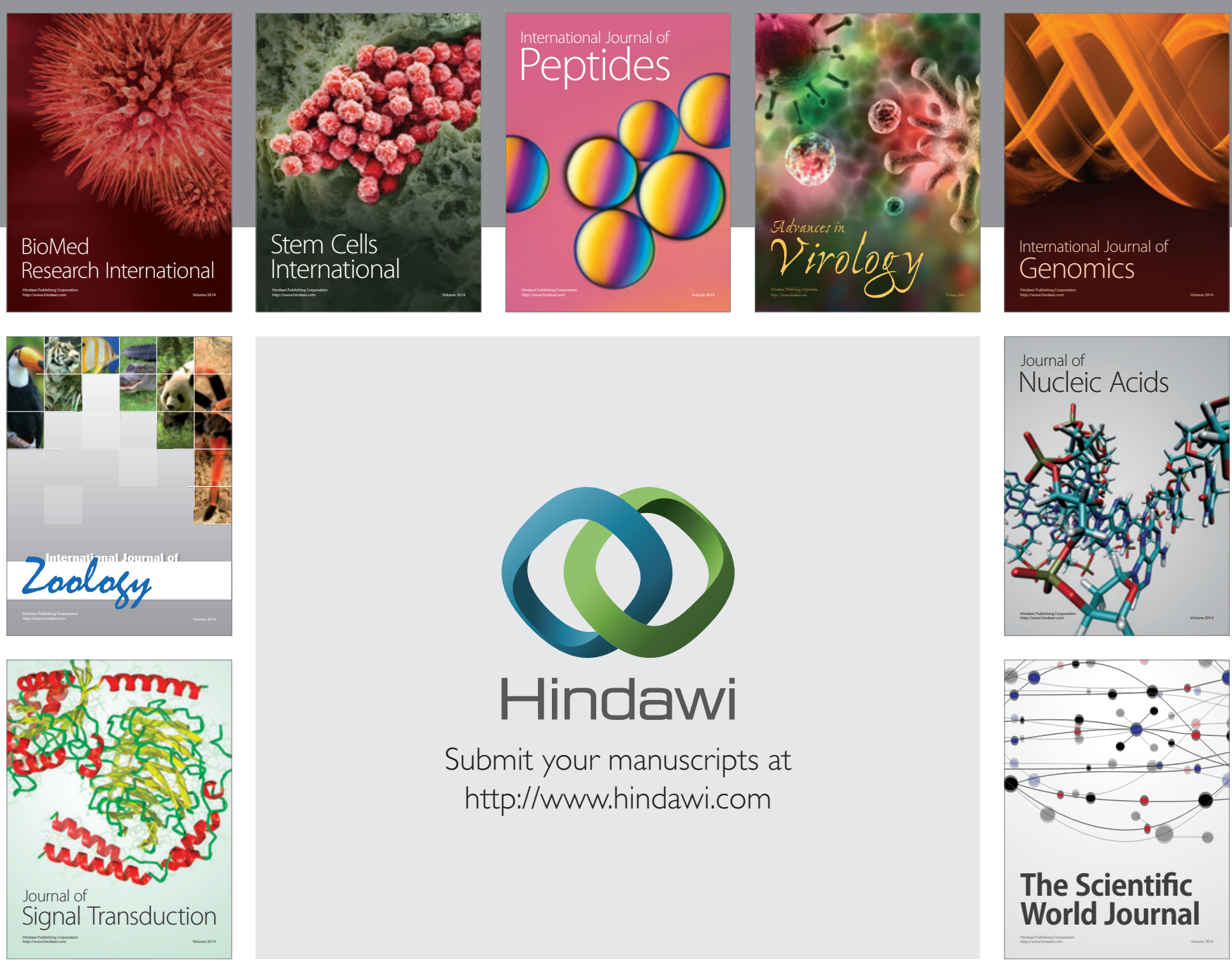

Submit your manuscripts at

http://www.hindawi.com
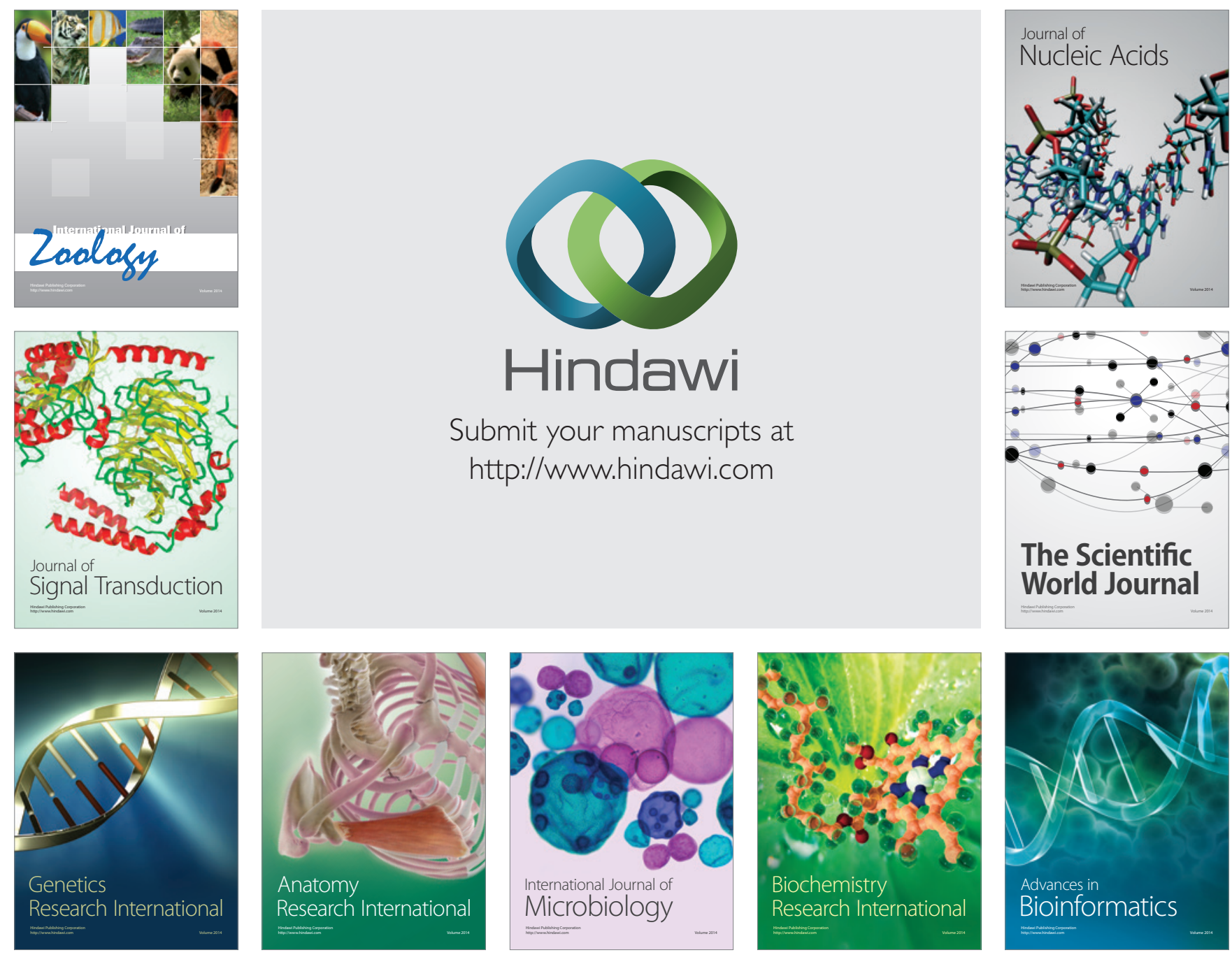

The Scientific World Journal
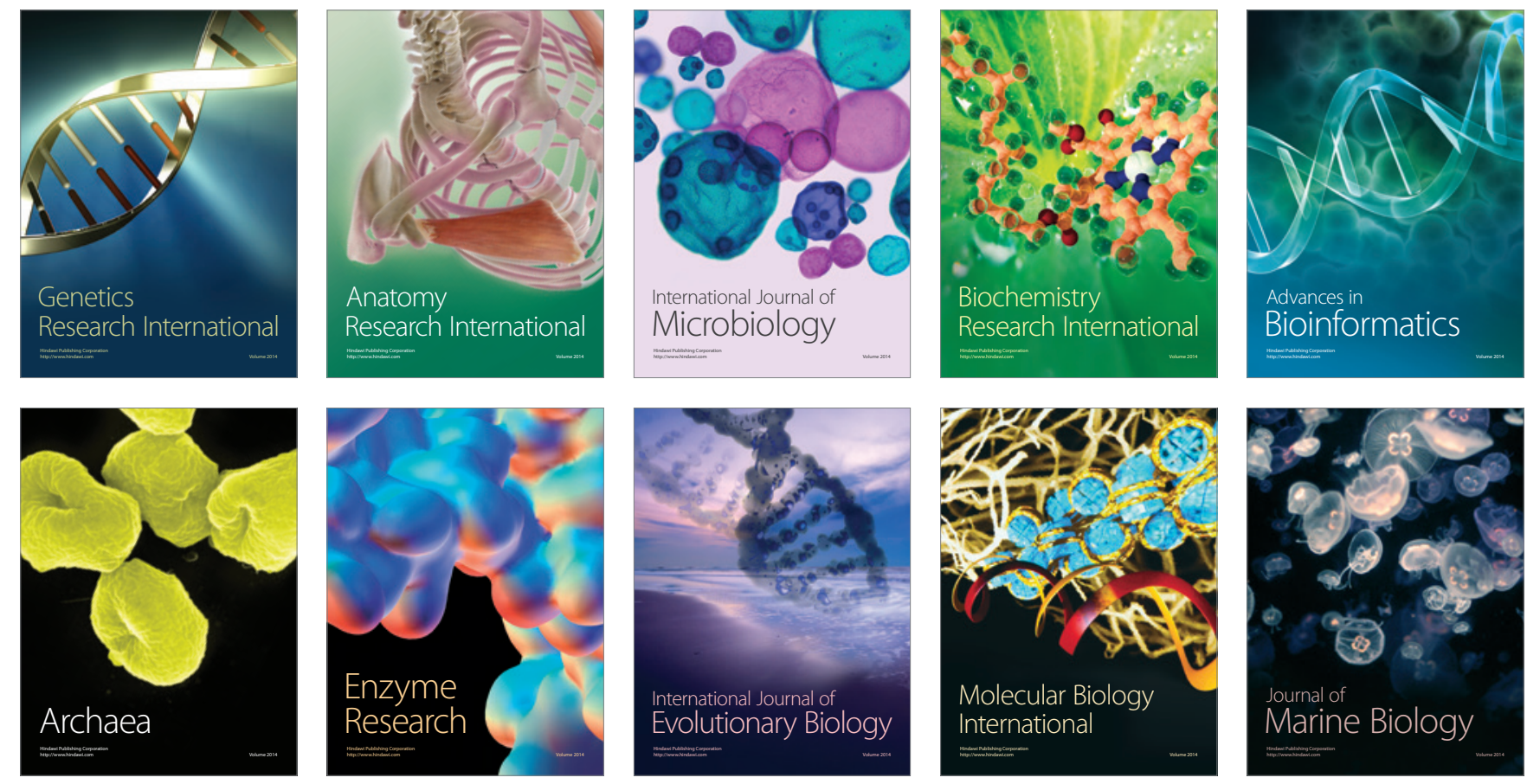